\title{
RESPONS PERTUMBUHAN TANAMAN TERUNG UNGU (Solanum melongena L.) DENGAN PERBEDAAN JARAK TANAM DAN PEMBERIAN POC DAUN GAMAL
}

\author{
Growth Response of Purple Eggplant (Solanum melongena L.) \\ By Plant Distance and Growing POC of Leaf Gamal
}

\author{
Bagus Prasetya ${ }^{1}$, Husain ${ }^{2}$, Ismaya N.R Parawansa ${ }^{3}$, dan Ummu Aimanah ${ }^{4}$ \\ ${ }^{1}$ Politeknik Pembangunan Pertanian Yogyakarta-Magelang \\ ${ }^{2}$ Dinas Pertanian Kabupaten Tojo Una-Una, Sulawesi Tengah \\ ${ }^{3}$ Pusat Pendidikan Pertanian Kementerian Pertanian \\ ${ }^{4}$ Politeknik Pembangunan Pertanian Gowa \\ e-mail: ismaya_p@yahoo.co.id
}

Received: 22 Maret 2021; Accepted: 26 Mei 2021; Published: 25 Juni 2021

\begin{abstract}
ABSTRAK
Pupuk organik dapat berbentuk padat maupun cair. Kelebihan pupuk organik cair (POC) adalah unsur hara yang dikandungnya lebih cepat tersedia dan mudah diserap akar tanaman. Kajian ini bertujuan untuk mengetahui respons pertumbuhan tanaman terung ungu (Solanum molongena L.) terhadap jarak tanam dan Pemberian POC daun gamal. Kajian dilaksanakan di Kelompoktani Ajulukana, Desa Sokkolia, Kecamatan Bontomarannu, Kabupaten Gowa pada Bulan Maret sampai Mei 2017. Kajian dilaksanakan dalam bentuk demonstrasi plot yang terdiri dari 4 perlakuan yaitu K1 (jarak tanam $60 \mathrm{~cm}$ x $70 \mathrm{~cm}$ diberi POC daun gamal $180 \mathrm{~mL} /$ plot), K2 (jarak tanam $100 \mathrm{~cm} \times 150 \mathrm{~cm}$ tanpa POC daun gamal), K3 (jarak tanam $100 \mathrm{~cm} \times 150$ $\mathrm{cm}$ diberi POC daun gamal $180 \mathrm{~mL} / \mathrm{plot}$ ) dan $\mathrm{K} 4$ (jarak tanam $60 \mathrm{~cm} \times 70 \mathrm{~cm}$ tanpa POC daun gamal). Hasil penelitian menunjukkan bahwa perlakuan K4 memberikan tinggi tanaman yang tertinggi mulai dari 1 sampai 4 MST, dan berbeda nyata dengan perlakuan lainnya pada 1 dan 2 MST. Sedangkan pada pengamatan jumlah daun, K4 menghasilkan jumlah daun terbanyak pada 1 MST, tetapi pada $2-4$ MST K3 memberikan jumlah daun terbanyak walaupun berbeda tidak nyata dengan K3.
\end{abstract}

Kata kunci : Jarak tanam, terung ungu (Solanum molongena L.), POC daun gamal

\section{ABSTRACT}

Organic fertilizers can be solid or liquid. The advantage of liquid organic fertilizer (POC) is that the nutrients it contains are more readily available and can be easily absorbed by plant roots. This study aims to determine the response to the growth of purple eggplant (Solanum molongena L) to plant spacing and giving gamal Leaves POC. The study was conducted in Ajulukana farmer group of Sokkolia Village, Bontomarannu district, Gowa Regency from March to May 2017. The study was carried out in the form of a demonstration plot consisting of 4 treatments, namely $K 1$ (spacing $60 \mathrm{~cm} \times 70 \mathrm{~cm}$ given POC of gamal leaves $180 \mathrm{~mL} / \mathrm{plot}$ ), K2 (spacing of $100 \mathrm{~cm} \times 150 \mathrm{~cm}$ without POC of gamal leaves), K3 (spacing $100 \mathrm{~cm}$ $x 150 \mathrm{~cm}$ given gamal leaves POC $180 \mathrm{~mL} /$ plot) and $K 4$ (spacing $60 \mathrm{~cm} \times 70 \mathrm{~cm}$ without gamal leaves $P O C)$. The results showed that $K 4$ treatment gave the highest plant height ranging from 1 to 4 WAP, and was significantly different from other treatments at 1 and 2 WAP. Whereas in observing the number of leaves, $K 4$ produced the highest number of leaves at 1 MST, but at 2 - 4 MST K3 gave the highest number of leaves even though it was not significantly different from $K 3$.

Keywords: Plant spacing, purple eggplant (Solanum molongena L.), gamal leaves POC 


\section{PENDAHULUAN}

Di Indonesia kebutuhan tanaman hortikultura cukup besar, salah satunya adalah buah terung yang dikonsumsi sebagai sayur. Kepopuleran terung cukup tinggi karena hampir semua kalangan dari berbagai daerah di Indonesia mengkonsumsi buah ini. Dari catatan sejarah, daerah/negara sebagai asal tanaman terung terletak di Asia, yakni India dan Birma. Menurut penelitian, sejak ratusan tahun lalu, terung mulanya hanya tumbuh liar. Namun kemudian setelah diketahui rasanya enak dan bermanfaat terung kemudian dibudidayakan di daerah tersebut. Di Afrika juga ditemukan plasma nutfah (sumber genetik) tanaman terung. Salah satunya adalah engkol (Solanum marcrocarpon). Jadi hakikatnya, tanaman terung merupakan tanaman asli daerah tropis.

Seiring dengan kemajuan teknologi beberapa produksi pertanian masih dapat ditingkatkan melalui upaya intensifikasi pertanian. Berkenaan dengan itu dalam proses pertumbuhan tanaman sangat dipengaruhi oleh tingkat kesuburan tanah. Salah satu cara untuk meningkatkan kesuburan tanah yaitu melalui pemupukan, agar tanaman tumbuh dengan baik dan hasil panen melimpah (Oviyanti dkk, 2016). Manfaat pupuk dalam budidaya tanaman pertanian sangat penting untuk mengetahui pertumbuhan dan perkembangan dari suatu tanaman tersebut, namun dewasa ini banyak petani yang membudidayakan tanaman terung dengan menggunakan bahan kimia, yakni untuk pemupukan dan pemacu pertumbuhan tanaman. Tanpa disadari penggunaan pupuk kimia yang tidak sesuai atau berlebihan akan memicu terjadinya perubahan-perubahan kondisi tanah, baik sifat fisik tanah maupun sifat kimia tanah, selain itu juga menyebabkan kemampuan tanah mendukung ketersediaan hara dan kehidupan mikroorganisme dalam tanah menurun, oleh karena itu jika tidak segera diatasi maka dalam jangka waktu tidak terlalu lama lahan-lahan tersebut tidak mampu lagi berproduksi secara optimal dan berkelanjutan, tetapi penggunaan pupuk organik mampu menjadi solusi dalam mengurangi pemakaian pupuk anorganik yang berlebihan (Seni, dkk, 2013).

Pupuk organik merupakan pupuk yang berasal dari pelapukan sisa makhluk hidup, seperti tanaman, hewan dan limbah organik. Pupuk ini umumnya merupakan pupuk lengkap artinya mengandung beberapa unsur hara makro dan mikro dengan jumlah yang tertentu. Pupuk organik dapat berbentuk padat maupun cair. Kelebihan pupuk organik cair adalah unsur hara yang dikandungnya lebih cepat tersedia dan mudah diserap akar tanaman. Selain dengan cara disiramkan pupuk cair dapat digunakan langsung dengan cara disemprotkan pada daun atau batang (Pardosi, dkk, 2014).

Usaha untuk meningkatkan kualitas hasil produksi tanaman sayuran dengan suatu sistim budidaya tanaman dan menambahkan POC pada tanaman sayuran yang merupakan teknologi yang mudah, ramah lingkungan serta berlanjutan dan menguntungkan. Bagi petani yang menuntut pemakaian pupuk yang murah dan praktis bisa diarahkan untuk menggunakan POC yang merupakan pupuk organik yang dapat dibuat dalam beberapa hari dan siap pakai dalam waktu singkat, selain itu pembuatan POC biayanya murah, tidak susah cara pembuatannya sehingga sangat efektif dan efisien bagi para petani dalam meningkatkan kesuburan tanah dan tanaman. Oleh karena itu, diperlukan suatu alternatif lain untuk mendapatkan pupuk yang murah dan ramah lingkungan.

Dalam pelaksanaan penelitian, penulis akan menggunakan daun gamal sebagai bahan dasar dalam pembuatan POC. Sehubungan dengan uraian tersebut, maka penelitian "Respon Pertumbuhan Tanaman Terung Ungu (Solanum Melongena L.) Terhadap Jarak Tanam dan Pemberian POC daun Gamal" menjadi menarik untuk diteliti.

\section{METODE PENELITIAN}

Kegiatan penelitian dilaksanakan di Kelompoktani Ajulukana, Desa Sokkolia, Kecamatan Bontomarannu, Kabupaten Gowa Provinsi Sulawesi Selatan, yaitu mulai Bulan Maret sampai bulan Juni 2017. Penelitian disusun dalam bentuk demonstrasi plot dengan 4 (empat) perlakuan, yaitu:

$$
\begin{aligned}
\mathrm{K} 1= & \text { Jarak tanam } 60 \mathrm{~cm} \times 70 \mathrm{~cm} \text { dengan } \\
& \text { pemberian POC/180 mL/plot, } \\
\mathrm{K} 2= & \text { Jarak tanam } 100 \mathrm{~cm} \times 150 \mathrm{~cm} \text { tanpa } \\
& \text { pemberian POC } \\
\mathrm{K} 3= & \text { Jarak tanam } 100 \mathrm{~cm} \times 150 \mathrm{~cm} \text { dengan } \\
& \text { pemberian POC } / 180 \mathrm{~mL} / \text { plot, } \\
\mathrm{K} 4= & \text { Jarak tanam } 60 \mathrm{~cm} \times 70 \mathrm{~cm} \text { tanpa } \\
& \text { pemberian POC. }
\end{aligned}
$$


Ukuran bedengan untuk penanaman terung ungu adalah lebar $150 \mathrm{~cm}$ dan panjang 650 $\mathrm{cm}$. Jumlah populasi dengan jarak tanam $60 \mathrm{~cm} x$ $70 \mathrm{~cm}$ sebanyak 22 tanaman, dan jumlah populasi dengan jarak tanam $100 \mathrm{~cm}$ x $150 \mathrm{~cm}$ sebanyak 10 tanaman.

Pemberian POC daun gamal, dengan cara disemprotkan pada bagian daun dan batang tanaman, waktu penyemprotan dilakukan pada waktu pagi hari antara pukul 07.00-10.00 WITA. Frekuensi pemberian POC dilakukan 3 kali, yaitu pada waktu tanaman berumur 10, 20, 30 HST. Pemberian POC daun gamal pada perlakuan K2 dengan populasi tananam 10 tanaman/plot diberi dosis $18 \mathrm{~mL} /$ liter air/pohon atau $180 \mathrm{~mL} /$ liter air/plot, sedangkan pada perlakuan K4 dengan populasi tanaman 22 tanaman/plot diberi dosis 7,5 mL/liter air/pohon atau $180 \mathrm{~mL} /$ liter air/plot. Parameter pengamatan, yakni: 1) tinggi tanaman, dengan melakukan pengukuran mulai dari permukaan tanah sampai pada titik tumbuh dan 2) jumlah daun, dengan melakukan penghitungan pada semua daun yang sudah terbuka sempurna. Untuk melihat perbedaan antar perlakukan dilakukan dengan menggunakan uji Standar Error (Kerlinger, 1990), dengan rumus:

$$
\mathrm{SE}=\mathrm{SD} / \mathrm{n}^{1 / 2}
$$

Keterangan: $\mathrm{SE}=$ standar error, $\mathrm{SD}=$ standar deviasi, $\mathrm{n}=$ jumlah sampel per plot

\section{HASIL DAN PEMBAHASAN}

\section{Tinggi Tanaman}

Data tinggi tanaman disajikan pada Tabel 1, sedangkan grafik pertumbuhan tanaman yang disertai dengan standar error disajikan pada gambar 1. Secara umum, perlakuan K4 memberikan hasil tinggi tanaman yang tertinggi, disusul perlakuan K1.

Tabel 1. Analisis uji standar eror dan rata-rata tinggi tanaman terung ungu pada umur 1 sampai 4 MST.

\begin{tabular}{ccccccc}
\hline \multirow{2}{*}{ Minggu } & \multicolumn{3}{c}{ K1 } & \multicolumn{3}{c}{ K4 } \\
\cline { 2 - 7 } & Rata-rata & SD & SE & Rata-rata & SD & SE \\
\hline I & 15,31 & 1,587 & 0,502 & 17,65 & 2,586 & 0,818 \\
II & 20,40 & 1,579 & 0,499 & 22,81 & 1,994 & 0,631 \\
III & 37,34 & 2,046 & 0,647 & 38,41 & 3,753 & 1,187 \\
IV & 51,95 & 4,477 & 1,416 & 52,46 & 3,517 & 1,112 \\
\hline Minggu & & K2 & & & K3 & \\
\hline I & 14,70 & 2,069 & 0,925 & 15,32 & 1,303 & 0,583 \\
II & 19,88 & 2,051 & 0,917 & 21,44 & 2,928 & 1,309 \\
III & 33,86 & 2,970 & 1,328 & 36,48 & 5,004 & 2,238 \\
IV & 50,08 & 2,794 & 1,250 & 50,78 & 2,242 & 1,003 \\
\hline
\end{tabular}

Hasil uji standar error pada Gambar 1 menunjukan rata-rata tinggi tanaman terung ungu (Solanum melongena. L) umur 1 sampai 4 MST terjadi peningkatan. Namun demikian tinggi tanaman terung ungu yang terbaik sampai dengan umur 4 MST diperoleh dari perlakuan K4 (jarak tanam $60 \mathrm{~cm} \times 70 \mathrm{~cm}$ tanpa POC daun gamal) yaitu $52,46 \mathrm{~cm}$ dan pertumbuhan tinggi tanaman yang terendah pada perlakuan K1 (jarak tanam $60 \mathrm{~cm} \times 70 \mathrm{~cm}$ diberi POC daun gamal) yaitu $51,95 \mathrm{~cm}$, sedangkan pertumbuhan tinggi tanaman pada perlakuan K2 (jarak tanam $100 \mathrm{~cm}$ $\mathrm{x} 150 \mathrm{~cm}$ tanpa POC daun gamal) memberikan nilai terendah yaitu $50,08 \mathrm{~cm}$ dan $\mathrm{K} 3$ (jarak tanam $100 \mathrm{~cm} \times 150 \mathrm{~cm}$ diberi POC) memberikan nilai tertinggi yaitu $50,78 \mathrm{~cm}$ pada pertumbuhan tinggi tanaman terung ungu umur 4 MST. Pertumbuhan tinggi tanaman merupakan salah satu bentuk pertumbuhan primer yang terjadi pada tanaman terung ungu, yakni proses pertambahan panjang pada tanaman, sebagai akibat adanya aktifitas pembelahan sel-sel yang terjadi pada jaringan meristem tanaman terung. POC adalah bahan-bahan alami yang mengandung unsur nitrogen. Gamal adalah salah satu tanaman famili leguminosae yang mengandung berbagai hara esensial yang cukup tinggi bagi pemenuhan kebutuhan hara tanaman. Jaringan daun tanaman gamal mengandung $3,15 \% \mathrm{~N}, 0,22 \% \mathrm{P}, 2,65 \% \mathrm{~K}, 1,35 \% \mathrm{Ca}$ dan 
0,41\% Mg (Ibrahim, 2002). Adanya perbedaan antara kedua perlakuan tersebut karena kandungan unsur $\mathrm{N}$ pada pupuk organik cair daun gamal. Menurut Dwijosaputro, (2002) menyatakan bahwa apabila unsur hara yang dibutuhkan tanaman berada dalam jumlah yang cukup tersedia dan unsur tersebut dapat diserap dengan baik maka tanaman akan tumbuh dengan optimal.

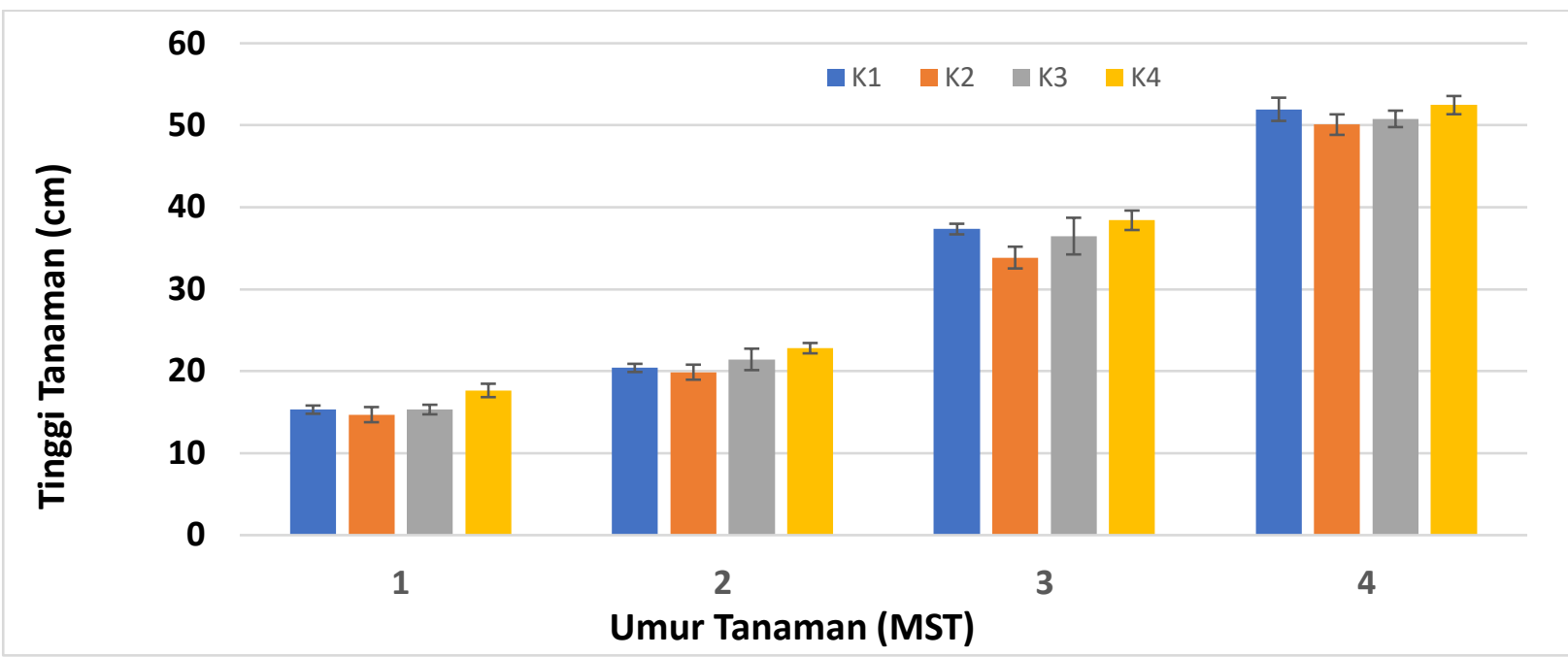

Gambar 1. Grafik pola pertumbuhan tinggi tanaman terung ungu pada umur 1 sampai 4 MST

Berdasarkan hasil uji standar error terhadap pertumbuhan tinggi tanaman terung ungu pada umur 1 sampai 4 minggu setelah tanam (MST) menunjukan bahwa pada 1 MST, K4 menghasilkan tinggi tanaman tertinggi yaitu $17,65 \mathrm{~cm}$ dan berbeda nyata dengan perlakuan lainnya. Pada 2 MST, K4 memberikan hasil tertinggi yaitu $22,81 \mathrm{~cm}$ walaupun berbeda tidak nyata dengan $\mathrm{K} 3$, dan berbeda nyata dengan $\mathrm{K} 2$ dan K1. Pada 3 MST, K4 memberikan hasil yang tertinggi yaitu $38,41 \mathrm{~cm}$ dan hanya berbeda nyata dengan K3. Pada 4 MST, K4 memberikan hasil tertinggi sebesar $52,46 \mathrm{~cm}$ dan berbeda tidak nyata dengan perlakuan lainnya.

\section{Jumlah Daun}

Data tinggi tanaman disajikan pada Tabel 2 , sedangkan grafik pertumbuhan tanaman yang disertai dengan standar error disajikan pada Gambar 2. Secara umum, perlakuan K3 dan K4 memberikan jumlah daun yang tertinggi dibandingkan dengan perlakuan lainnya.

Tabel 2. Analisis uji standar eror dan rata-rata jumlah daun terung ungu pada umur 1 sampai 4 MST

\begin{tabular}{ccccccc}
\hline \multirow{2}{*}{ Minggu } & \multicolumn{3}{c}{ K1 } & & \multicolumn{3}{c}{ K4 } \\
\cline { 2 - 7 } & Rata-rata & SD & SE & Rata-rata & SD & SE \\
\hline I & 4,30 & 0,483 & 0,153 & 5,30 & 0,675 & 0,213 \\
II & 4,90 & 0,738 & 0,233 & 5,80 & 0,632 & 0,200 \\
III & 7,40 & 0,699 & 0,221 & 7,60 & 1,174 & 0,371 \\
IV & 9,40 & 0,843 & 0,267 & 9,80 & 0,422 & 0,133 \\
\hline \multirow{2}{*}{ Minggu } & & K2 & & & \multirow{2}{*}{ K3 } & \\
\hline I & 4,80 & 0,447 & 0,200 & 5,20 & 0,447 & 0,200 \\
II & 5,00 & 0,000 & 0,000 & 6,00 & 0,000 & 0,000 \\
III & 7,20 & 0,447 & 0,200 & 8,20 & 0,447 & 0,200 \\
IV & 9,20 & 0,447 & 0,200 & 9,80 & 0,447 & 0,200 \\
\hline
\end{tabular}




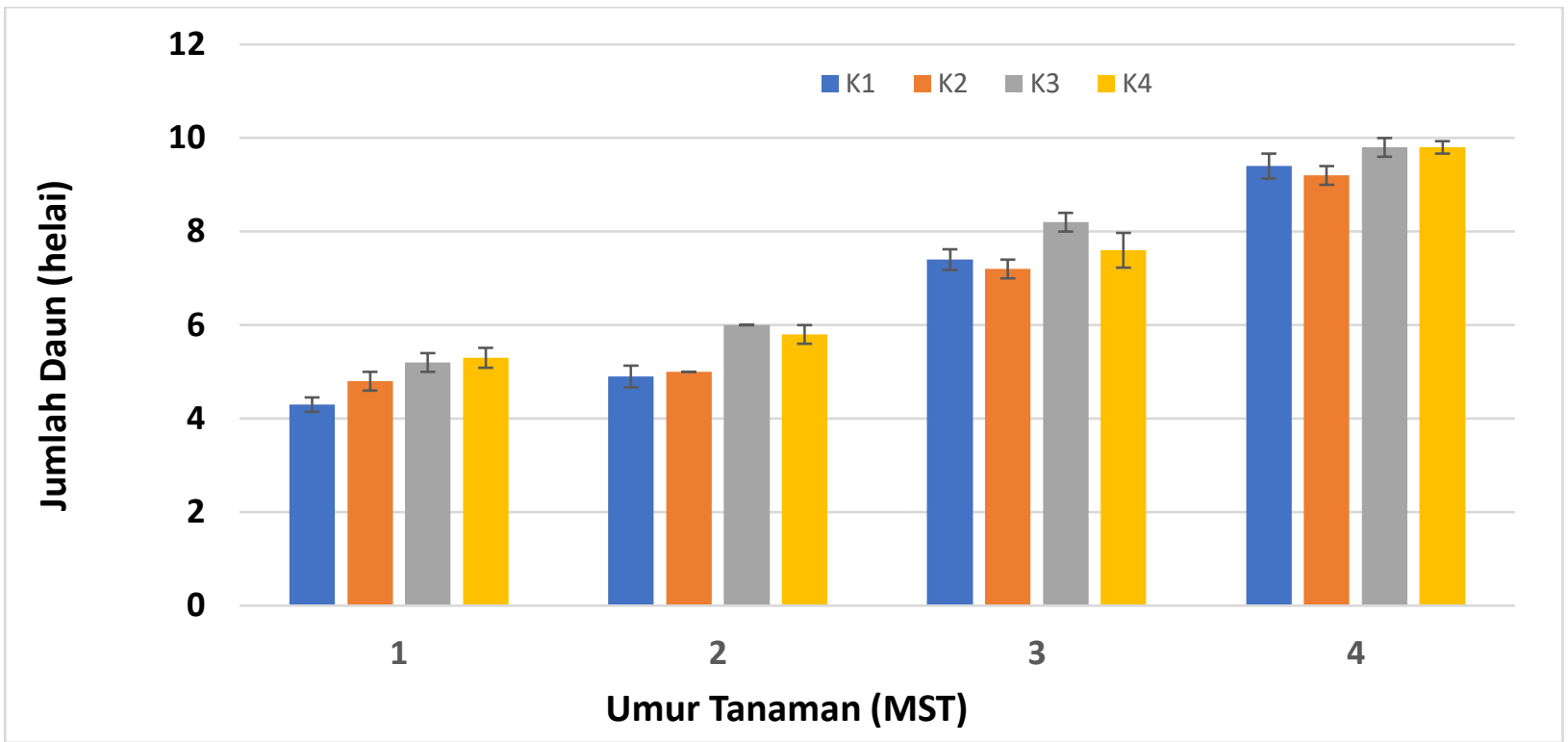

Gambar 2. Grafik pola pertambahan jumlah daun tanaman terung ungu pada umur 1-4 MST

Berdasarkan hasil uji standar error terhadap pertambahan jumlah daun terung ungu pada umur 1 sampai 4 minggu setelah tanam (MST) menunjukan bahwa pada 1 MST, K4 menghasilkan jumlah daun tertinggi yaitu 5,3 helai dan berbeda tidak nyata dengan $\mathrm{K} 3$ serta berbeda nyata dengan perlakuan lainnya. Pada 2 MST, K3 memberikan hasil jumlah daun tertinggi yaitu 6 helai walaupun berbeda tidak nyata dengan $\mathrm{K} 4$, dan berbeda nyata dengan $\mathrm{K} 2$ dan K1. Pada 3 MST, K3 memberikan hasil yang tertinggi yaitu 8,2 helai walaupun berbeda tidak nyata dengan $\mathrm{K} 4$, dan berbeda nyata dengan $\mathrm{K} 1$ dan K2. Pada 4 MST, K3 dan K4 memberikan hasil tertinggi sebesar 9,8 helai dan hanya berbeda nyata dengan $\mathrm{K} 2$.

Hasil analisis uji standar error pada Gambar 2 menunjukan perkembangan jumlah daun tanaman terung ungu umur 1 sampai 4 MST. K4 (jarak tanam $60 \mathrm{~cm}$ x $70 \mathrm{~cm}$ tanpa POC daun gamal) memberikan hasil tertinggi mencapai 9,8 (helai) dan nilai terendah pada perlakuan K1 (jarak tanam $60 \mathrm{~cm}$ x $70 \mathrm{~cm}$ diberi POC daun gamal $180 \mathrm{ml} /$ plot) mencapai 9,4 (helai). Sedangkan pertumbuhan jumlah daun pada perlakuan K3 ( jarak tanam $100 \mathrm{~cm} \times 150$ $\mathrm{cm}$ diberi POC daun gamal $180 \mathrm{ml} / \mathrm{plot}$ ) memberikan nilai tertinggi mencapai 9,8 (helai) dan perlakuan K2 (jarak tanam $100 \mathrm{~cm}$ x $150 \mathrm{~cm}$ tanpa POC) memberikan nilai terendah yaitu 9,2 (helai).

Seiring dengan pertumbuhan tinggi tanaman, jumlah daun pun akan terus bertambah sesuai umur tanaman. Hal tersebut disebabkan oleh karena pembelahan sel pada jaringan meristem yang berada pada ujung tanaman akan mempengaruhi pertumbuhan pada semua bagian tanaman termasuk daun. Data hasil pengamatan jumlah daun yang tertera pada Tabel 2 menunjukan adanya pertumbuhan jumlah daun yang masih relatif sama antara tanaman pada petak perlakuan jarak tanam diberi POC daun gamal dan tanaman pada petak perlakuan jarak tanam tanpa POC daun gamal sampai umur 4 mst. Meskipun pada Tabel 2 terlihat adanya perbedaan angka jumlah daun, namun secara statistis perbedaan tersebut tidak menunjukan pengaruh nyata terhadap pertumbuhan jumlah daun tanaman terung ungu. Hal itu terbukti dengan hasil analisis uji standar eror jumlah daun tanaman terung ungu pada umur 1, 2, 3 dan 4 mst. Hal ini disebabkan karena ketersediaan unsur nitrogen sebagai unsur hara terdapat pada pupuk organik cair daun gamal yang cukup untuk perkembangan dan pertumbuhan tanaman, ini sangat penting peranannya dalam proses pertumbuhan vegetatif tanaman. Hal ini sejalan dengan pernyataan dari Setiawan (2005), yang menyatakan bahwa, unsur nitrogen berfungsi untuk merangsang pertumbuhan tanaman secara keseluruhan, termasuk daun.

\section{KESIMPULAN}

Berdasarkan hasil analisis uji standar error menunjukan bahwa respons pertumbuhan tinggi tanaman dan pemberian POC daun gamal 
pada perlakuan K1 (jarak tanam $60 \mathrm{~cm} \times 70 \mathrm{~cm}$ diberi POC daun gamal), tidak beda nyata terhadap perlakuan K4 (jarak tanam $60 \mathrm{~cm}$ x 70 $\mathrm{cm}$ tanpa POC daun gamal), sedangkan perlakuan K3 (jarak tanam $100 \mathrm{~cm} \times 150 \mathrm{~cm}$ diberi POC daun gamal) tidak memberikan pengaruh beda nyata terhadap perlakuan K2 (jarak tanam $100 \mathrm{~cm}$ $\mathrm{x} 150 \mathrm{~cm}$ tanpa POC daun gamal).

\section{DAFTAR PUSTAKA}

Ibrahim, B. 2002. Integrasi Jenis Tanaman Pohon Leguminosae Dalam Sistem Budidaya Pangan Lahan Kering dan Pengaruhnya terhadap Sipat Tanah, Erasi dan Produktifitas Lahan. Disertasi. Program Pasca Sarjana Universitas Hasanuddin, Makassar.

Kerlinger, F.N. 1990. Asas-Asas Penelitian Behavioral (Terjemahan L.R. Simatupang). Gadjah Mada Univ. Press, Yogyakarta.
Oviyanti F, 2016. Pengaruh Pemberian Pupuk Organik Cair Daun Gamal (Gliricidia sepium (Jacq.) Kunth ex Walp.) Terhadap Pertumbuhan Tanaman Sawi (Brassica juncea L.)

Pardosi, A. H., Irianto dan Mukhsin. 2014. Respons Tanaman Sawi terhadap Pupuk Organik Cair Limbah Sayuran pada Lahan Kering Ultisol. Jambi: Universitas Jambi. Prosiding Seminar Nasional Lahan Suboptimal 2014, Palembang 26-27 September 2014 ISBN: 979-587-529-9.

Seni, I. A.Y., I Wayan, D.A., dan Ni Wayan, S.S. 2013. Analisis Kualitas Larutan MOL (Mikoorganisme Lokal) Berbasis Daun Gamal (Gliricidia Sepium). Denpasar: Universitas Udayana. E-Jurnal Agroekoteknologi Tropika ISSN: 2301 6515 Vol. 2, No. 2, April 2013.

Setiawan IS, 2005. Memanfaatkan Kotoran Ternak. Jakarta. Penebar Swadaya. 